Short Note

\title{
Structure of Methyl 1-oxo-3,5-diphenylcyclohexene-6-carboxylate
}

\author{
Abraham F. Jalbout 1,2, ${ }^{*}$, Flavio F. Contreras-Torres 1, Gabriela M. Lobo 3 and Jaimi E. Charris 3 \\ 1 Instituto de Química, Universidad Nacional Autónoma de México, México D.F., A. Postal, 04510, México. \\ Department of Chemistry, The University of Arizona, Tucson, AZ 85721 USA. \\ 3 Laboratorio de Síntesis Orgánica, Facultad de Farmacia, Universidad Central de Venezuela, Caracas 1051, \\ Venezuela. \\ * Author to whom correspondence should be addressed. E-mail: ajalbout@u.arizona.edu; Tel: \\ +1-520-621-6761; Fax: +1-520-621-8047
}

Received: 8 May 2007 / Accepted: 4 September 2007 / Published: 19 November 2007

\section{Introduction}

The exploration of a simple molecule with different functionalities for the synthesis of heterocycles is a worthwhile contribution in the chemistry of heterocycles. In fact, 6-ethoxycarbonyl-3,5-diarylcyclohexenone has been used as an effective synthon in some projected syntheses of benzoselenadiazoles/thiadiazoles ${ }^{1}$, spirocyclohexanones ${ }^{2}$, carbazole derivatives ${ }^{3}$, fused isoxazoles and pyrazoles ${ }^{4,5}$. The intermediate present in this communication has been chosen by us as a promising starting material to develop pyrazole rings with antimalarial and antibacterial activities $^{6}$

Compounds $\mathbf{1 a}, \mathbf{b}$ were synthesised by a base-catalysed Claisen-Schmidt condensation of 4-chlorobenzaldehyde with the appropriate acetophenone. These ketones on treatment with methyl 3-oxobutanoate in the presence of sodium methoxide yield methyl 6-(4-chlorophenyl)-4-(4-methylphenyl)cyclohex-3-en-2-one-1-carboxylate ${ }^{7}$ 1a (R: 4-Cl; $\mathrm{R}_{2}$ : 4-Me in Scheme 1) or methyl-1-oxo-3,5-diphenylcyclohexene-6-carboxylate $\mathbf{1 b}\left(\mathrm{R}_{1}=\mathrm{R}_{2}: \mathrm{H}\right.$ in Scheme 1, see also Figure 1). In the present communication, we report the formation of $\mathbf{1 b}$ and its characterisation by elemental analysis as well as IR, ${ }^{1} \mathrm{H}$ NMR, ${ }^{13} \mathrm{C}$ NMR, COSY, and HETCOR spectral and crystallographic studies. The analysis of $\mathbf{1 a}$ has been previously reported ${ }^{7}$.

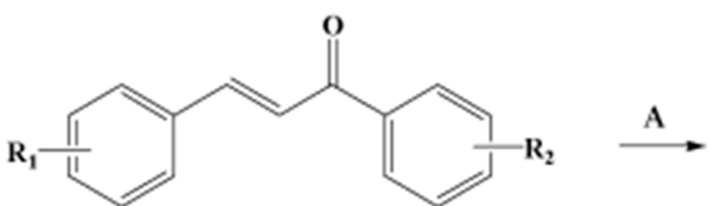

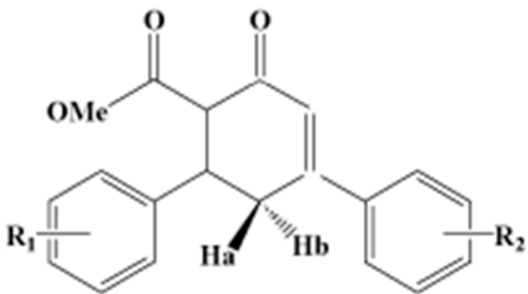

1 b

Scheme 1. Chemical synthesis of methyl 1-oxo-3,5-diphenylcyclohexene-6-carboxylate 1b $\left(\mathrm{R}_{1}=\mathrm{R}_{2}: \mathrm{H}\right)$. A represents $\mathrm{CH}_{3} \mathrm{COCH}_{2} \mathrm{CO}_{2} \mathrm{CH}_{3}, \mathrm{NaOMe}, \mathrm{MeOH}$, rt. 


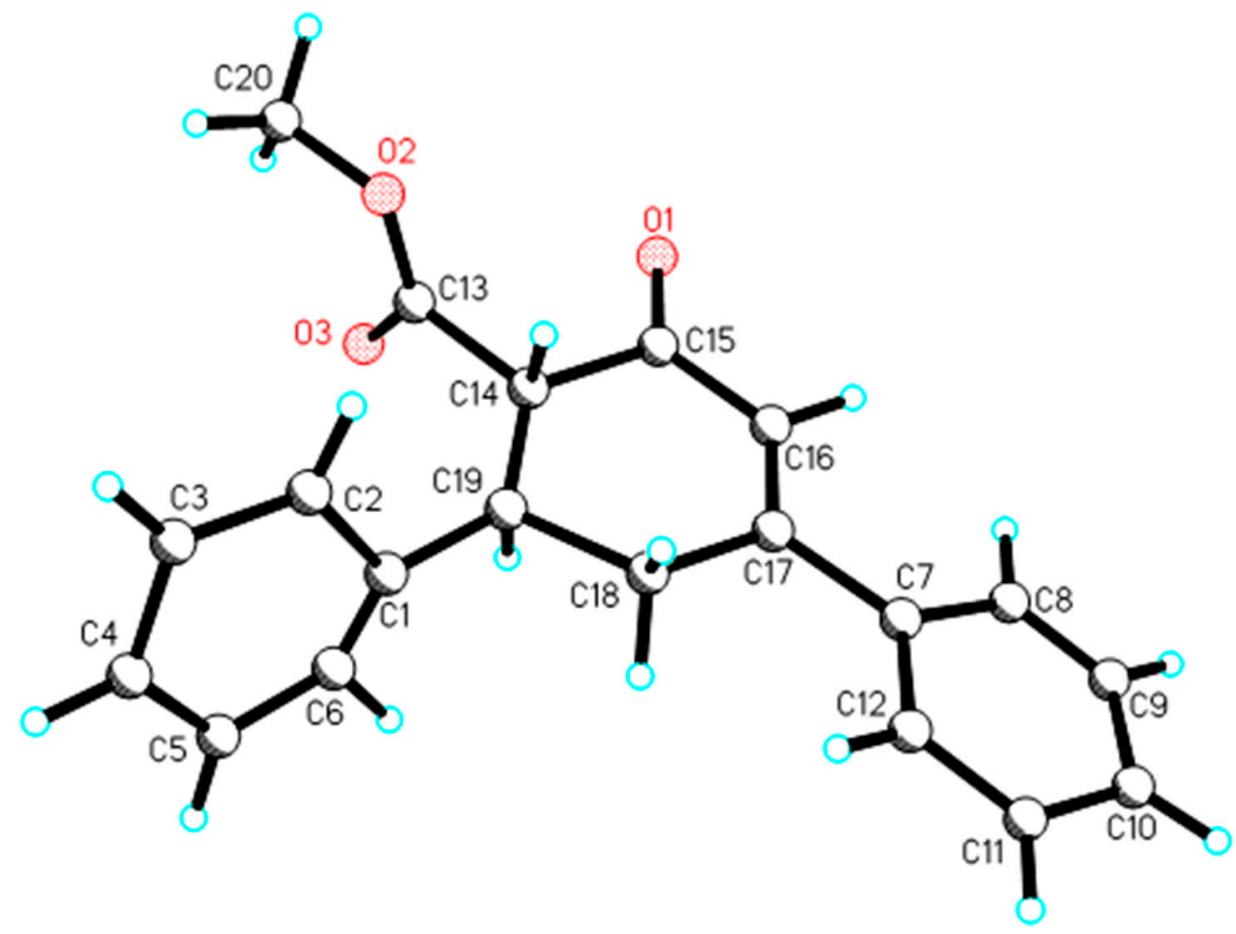

Figure 1. View of the structure of $\mathbf{1 b}$ with the atom numbering for carbon and oxygen atoms, showing displacement ellipsoids at the $50 \%$ probability level.

The IR spectrum of $\mathbf{1 b}$ showed bands around 1734, 1657 and $1590 \mathrm{~cm}^{-1}$ corresponding to $\alpha, \beta$-unsaturated carbonyl, carbonyl ester and $\mathrm{C}=\mathrm{C}$ bonds, respectively. The ${ }^{1} \mathrm{H}$ NMR spectrum exhibited a doublet and doublet of triplets at 3.06 and 3.13 ppm for $\mathrm{H}_{4 a}, 4 \mathrm{~b}$, respectively, those protons are coupling with the proton in position 2 of the cyclohexene ring. The absence of doublets corresponding to the alkene structure of the starting material indicates that an addition reaction has indeed taken place. ${ }^{13} \mathrm{C}$ NMR confirms the presence of carbonyl $\mathrm{C}$ atoms of a ketone and an ester at 175 and $194 \mathrm{ppm}$. The assignments were confirmed by COSY and HETCOR spectra.

\section{Experimental}

Melting points were determined on a Thomas micro hot stage apparatus and are uncorrected. Infrared spectra were determined as $\mathrm{KBr}$ pellets on a Shimadzu model 470 spectrophotometer. The ${ }^{1} \mathrm{H}$ NMR, ${ }^{13} \mathrm{C}$ NMR, COSY and HETCOR spectra were recorded using a Jeol Eclipse $270 \mathrm{MHz}$ spectrometer. Chemical shifts are expressed relative to residual chloroform. Central Service of Universidad de Málaga, Málaga-España performed elemental analyses, results were within $\pm 0.4 \%$ of predicted values for all compounds. Chemical reagents were obtained from Aldrich Chemical Co., USA. All solvents were distilled and dried with the usual desiccant.

\section{X-ray Crystallographic Data Collection and Structural Determination.}

Single-crystal X-ray diffraction measurement of the compounds were carried out with a Bruker Smart 1000 CCD diffractometer equipped with a graphite crystal monochromator situated in the incident beam for data collection at 298(2) K. The lattice parameters were obtained by least-squares refinement of the diffraction data of 9336 reflections, and data collections were performed with Mo K $\alpha$ radiation $(\lambda=0.71073 \AA)$ by $\omega$ scan mode in the range of $1.96<\theta<25.10^{\circ}$. All of the measured independent reflections were used in the structural analysis, and semiempirical absorption corrections were applied using the SADABS program. The maximum and minimum transmission factors were 0.980 and 0.961 . The program SAINT14 was used for integration of the diffraction profiles. The structure was solved by direct methods using the SHELXS97 program of the SHELXTL 
package and refined with SHELXL9715. The non-hydrogen atoms were located in successive difference Fourier syntheses. The final refinement was performed by full-matrix least-squares methods with anisotropic thermal parameters for all of the non-hydrogen atoms on F2. All of the hydrogen atoms were generated theoretically onto the specific atoms and refined isotropically with fixed thermal factors. A summary of the crystallographic data and structure refinement of $\mathbf{1 b}$ is listed in Table 1, and selected bond lengths and bond angles are listed in Table 2.

Table 1. Crystallographic data for compound $1 \mathrm{~b}$

\begin{tabular}{llll}
\hline Parameter & Compound 1b & Parameter & Compound 1b \\
\hline formula & $\mathrm{C}_{20} \mathrm{H}_{18} \mathrm{O}_{3}$ & $\rho($ calcd $), \mathrm{g} \mathrm{cm}^{-3}$ & 1.331 \\
$\mathrm{fw}$ & 306.34 & $F(000)$ & 648 \\
lattice & Monoclinic & $\mu($ Mo KR $), \mathrm{cm}^{-1}$ & 0.089 \\
$a, \AA$ & $14.885(7)$ & diffractometer & APEX \\
$b, \AA$ & $11.172(5)$ & radiatn $\lambda, \AA$ & 0.71073 \\
$c, \AA$ & $9.367(4)$ & temp, ${ }^{\circ} \mathrm{C}$ & 25 \\
$\beta$, deg & $101.161(12)$ & $R(I>2.00 \sigma(I)) a$ & 0.3288 \\
$V, \AA^{3}$ & $1528.2(12)$ & $R \mathrm{w}($ all data $) b$ & 0.6053 \\
space group & $\mathrm{P} 2(1) / \mathrm{c}$ & no. of observs & 2671 (all data) \\
$\mathrm{Z}$ & 4 & no. of variables & 210 \\
\hline
\end{tabular}

Table 2. Selected bond distances $(\AA)$, angles (deg) and torsion angles (deg) for compound $\mathbf{1 b}$ at $298 \mathrm{~K}$

\begin{tabular}{ll}
\hline \multicolumn{1}{c}{ Distances } \\
$\mathrm{C}(15)-\mathrm{O}(1)$ & $1.20(2)$ \\
$\mathrm{C}(15)-\mathrm{C}(16)$ & $1.41(2)$ \\
$\mathrm{C}(15)-\mathrm{C}(14)$ & $1.52(3)$ \\
$\mathrm{C}(13)-\mathrm{O}(3)$ & $1.18(3)$ \\
$\mathrm{C}(13)-\mathrm{O}(2)$ & $1.24(3)$ \\
$\mathrm{C}(13)-\mathrm{C}(14)$ & $1.50(3)$ \\
$\mathrm{C}(1)-\mathrm{C}(6)$ & $1.04(3)$ \\
$\mathrm{C}(1)-\mathrm{C}(19)$ & $1.36(3)$ \\
$\mathrm{C}(1)-\mathrm{C}(2)$ & $1.49(3)$ \\
$\mathrm{C}(7)-\mathrm{C}(12)$ & $1.34(3)$ \\
$\mathrm{C}(7)-\mathrm{C}(8)$ & $1.37(3)$ \\
$\mathrm{C}(7)-\mathrm{C}(17)$ & $1.50(3)$ \\
$\mathrm{C}(8)-\mathrm{C}(9)$ & $1.24(3)$ \\
& angles \\
$\mathrm{O}(1)-\mathrm{C}(15)-\mathrm{C}(16)$ & $126.9(19)$ \\
$\mathrm{O}(1)-\mathrm{C}(15)-\mathrm{C}(14)$ & $121.1(16)$ \\
$\mathrm{C}(16)-\mathrm{C}(15)-\mathrm{C}(14)$ & $112.0(18)$ \\
$\mathrm{O}(3)-\mathrm{C}(13)-\mathrm{O}(2)$ & $127(3)$ \\
$\mathrm{O}(3)-\mathrm{C}(13)-\mathrm{C}(14)$ & $116(3)$
\end{tabular}




$\begin{array}{cc}\text { O(2)-C(13)-C(14) } & 117(3) \\ \text { torsion angles } & \\ \mathrm{C}(12)-\mathrm{C}(7)-\mathrm{C}(8)-\mathrm{C}(9) & 3(3) \\ \mathrm{C}(17)-\mathrm{C}(7)-\mathrm{C}(8)-\mathrm{C}(9) & -174(2) \\ \mathrm{C}(7)-\mathrm{C}(8)-\mathrm{C}(9)-\mathrm{C}(10) & -4(4) \\ \mathrm{C}(8)-\mathrm{C}(9)-\mathrm{C}(10)-\mathrm{C}(11) & 7(4) \\ \mathrm{C}(9)-\mathrm{C}(10)-\mathrm{C}(11)-\mathrm{C}(12) & -10(4) \\ \mathrm{C}(8)-\mathrm{C}(7)-\mathrm{C}(12)-\mathrm{C}(11) & -4(3) \\ \mathrm{C}(17)-\mathrm{C}(7)-\mathrm{C}(12)-\mathrm{C}(11) & 172.4(19) \\ \mathrm{C}(10)-\mathrm{C}(11)-\mathrm{C}(12)-\mathrm{C}(7) & 8(3) \\ \mathrm{O}(1)-\mathrm{C}(15)-\mathrm{C}(16)-\mathrm{C}(17) & -173(3) \\ \mathrm{C}(14)-\mathrm{C}(15)-\mathrm{C}(16)-\mathrm{C}(17) & 8(4) \\ \mathrm{C}(15)-\mathrm{C}(16)-\mathrm{C}(17)-\mathrm{C}(18) & -10(3) \\ \mathrm{C}(15)-\mathrm{C}(16)-\mathrm{C}(17)-\mathrm{C}(7) & 174(2) \\ \mathrm{C}(12)-\mathrm{C}(7)-\mathrm{C}(17)-\mathrm{C}(16) & 168(2) \\ \mathrm{C}(8)-\mathrm{C}(7)-\mathrm{C}(17)-\mathrm{C}(16) & -15(3) \\ \mathrm{C}(12)-\mathrm{C}(7)-\mathrm{C}(17)-\mathrm{C}(18) & -7(3) \\ \mathrm{C}(8)-\mathrm{C}(7)-\mathrm{C}(17)-\mathrm{C}(18) & 169.5(19) \\ \mathrm{C}(16)-\mathrm{C}(17)-\mathrm{C}(18)-\mathrm{C}(19) & 21(3) \\ \mathrm{C}(7)-\mathrm{C}(17)-\mathrm{C}(18)-\mathrm{C}(19) & -163.7(18) \\ \mathrm{C}(6)-\mathrm{C}(1)-\mathrm{C}(19)-\mathrm{C}(14) & 127(4) \\ \mathrm{C}(2)-\mathrm{C}(1)-\mathrm{C}(19)-\mathrm{C}(14) & -58(4) \\ \mathrm{C}(6)-\mathrm{C}(1)-\mathrm{C}(19)-\mathrm{C}(18) & -75(3) \\ \mathrm{C}(2)-\mathrm{C}(1)-\mathrm{C}(19)-\mathrm{C}(18) & 100.6(19) \\ \mathrm{C}(17)-\mathrm{C}(18)-\mathrm{C}(19)-\mathrm{C}(14) & -29(3) \\ \mathrm{C}(17)-\mathrm{C}(18)-\mathrm{C}(19)-\mathrm{C}(1) & -175(3) \\ \mathrm{O}(3)-\mathrm{C}(13)-\mathrm{O}(2)-\mathrm{C}(20) & 10(4) \\ \mathrm{C}(14)-\mathrm{C}(13)-\mathrm{O}(2)-\mathrm{C}(20) & \\ \mathrm{C}(19)-\mathrm{C}(1)-\mathrm{C}(6)-\mathrm{C}(5) & \\ \mathrm{C}(2)-\mathrm{C}(1)-\mathrm{C}(6)-\mathrm{C}(5) & \\ & \end{array}$

\section{General procedure for the synthesis}

A mixture of sodium methoxide (catalytic), freshly distilled methyl 3-oxobutanoate (0.01 mol) and chalcone $(0.01 \mathrm{~mol})$ in $20 \mathrm{ml}$ of absolute methanol was stirred at room temperature over night. The resulting precipitate was collected by filtration, washed with methanol and bidistilled water. Crystallization from methanol gave crystals of $\mathbf{1 b}$ suitable for single-crystal X-ray diffraction.

\section{Methyl 1-oxo-3,5-diphenylcyclohexene-6-carboxylate (1b)}

Yield 90\%; m.p. 110-112 ${ }^{\circ} \mathrm{C}$; IR ( $\left.\mathrm{cm}^{-1}, \mathrm{KBr}\right): 1734$ (CO), 1657 (CO), 1590 (C=C). ${ }^{1} \mathrm{H}^{\mathrm{N} M R} \mathrm{CDCl}_{3}$ : $\delta 3.06\left(\mathrm{~d}, 1 \mathrm{H}, \mathrm{H}_{4 a}, \mathrm{~J}: 12.5 \mathrm{~Hz}\right), 3.13\left(\mathrm{dt}, 1 \mathrm{H}, \mathrm{H}_{4 b}, \mathrm{~J}: 11,5,7.71,1.98 \mathrm{~Hz}\right), 3.58\left(\mathrm{~s}, 3 \mathrm{H}, \mathrm{OCH}_{3}\right), 3.81(\mathrm{dd}, 2 \mathrm{H}$, $\left.\mathrm{H}_{5,6}, \mathrm{~J}: 5.44,2.23 \mathrm{~Hz}\right), 6.56$ (d, 1H, H2, J:1.98 Hz), 7.42-7.29 (m, 5H, Ar), 7.55-7.51 (m, 5H, Ar). ${ }^{13} \mathrm{C}$ NMR: 36.1, 44.1, 52.2, 59.6, 124.1, 126.2, 127.2, 127.6, 128.9, 130.6, 137.7, 141.1, 158.8, 174.8, 194.0. Anal. Calcd. For $\mathrm{C}_{20} \mathrm{H}_{18} \mathrm{O}_{3}: \mathrm{C}, 78.41 ; \mathrm{H}, 5.92$. Found. C, 78.63; H, 5.84. 


\section{References}

1. (a) Bhaskar, R.D.; Somasekhar, R.A.; Padmavathi, V. Synthesis of Annelated 1,2,3-Selena- or -Thia-diazoles. J. Chem. Research (S) 1998, 784-785. (b) Padmavathi, V.; Reddy, B.J.M.; Balaiah, A; Reddy, K.V.; Reddy, D.B. Synthesis of Some Fused Pyrazoles and Isoxazoles. Molecules 2000, 5, 1281-1286. (c) Balasankar, T.; Gopalakrishnan, M.; Nagarajan, S. Synthesis and Antibacterial Activity of Some 5-(4-biphenylyl)-7-aryl[3,4-d] [1,2,3]-benzothiadiazoles. Eur. J. Med. Chem. 2005, 40, 728-731.

2. Stanetty, P.; Kremslehner, M. Synthesis of thieno[3,2-d][1,2,3]thiadiazoles. New Mechanistic Aspects of the Hurd-Mori Reaction. Heterocycles 1998, 48, 259-266.

3. Stanetty, P.; Kremslehner, M.; Müllner, M. Application of the Hurd-Mori-reaction for the Synthesis of Tricyclic Annelated 1,2,3-thiadiazoles. J. Heterocycl. Chem. 1996, 33, 1759-1763.

4. Lewis, G.; Nelson, P. 3-[(1,2,3-Thiadiazol-5-ylthio)methyl]cephalosporins. J. Med. Chem. 1979, 22, 1214-1218.

5. Padmavathi, V.; Sharmila, K.; Padmaja, A.; Reddy, B.D. An efficient synthesis of 6,8-diarylcarbazoles via Fischer indole cyclizations. Heterocycl. Commun. 1999, 5, 451-456.

6. Lobo, G.; Charris, J. (unpublished results).

7. Jalbout, A.F.; Contreras-Torres, F.F.; Lobo, G.M.; Charris, J.E. Structure of Methyl (1S, 6S) 6-(4-chlorophenyl)-4-(4-methylphenyl)cyclohex-3-en-2-one-1-carboxylate. Molecules 2007 (accepted).

(C) 2007 by MDPI (http://www.mdpi.org/). Reproduction is permitted for noncommercial purposes. 